\title{
MEMBANGUN MODEL PENYEBARAN HAMA DAN PENYAKIT PADA BAWANG MERAH PALU (Allium ascalonicum L.)
}

\author{
M. Mutmainnah1, R. Ratianingsih² dan N. Nacong ${ }^{3}$ \\ 1,2,3 Program Studi Matematika Jurusan Matematika FMIPA Universitas Tadulako \\ Jalan Soekarno-Hatta Km. 09 Tondo, Palu 94118, Indonesia. \\ 1mhaznii@gmail.com, 2ratianingsih@yahoo.com, 3nasria_nacong@gmail.com
}

\begin{abstract}
Caterpillar leaves (spodoptera exigue) and fungi altenaria porriare plant distractor organism that become a factor of some problems faced on onion (alliumascalonicum /.) cultivation. The objectives of this research is to govern a mathematical model of the pest and disease spread of Palu onion. The model divides the onion population into 6 sub populations are, a population of Palu onion that potentially be infected by pests and disease $(S)$, a population of Palu onion that potentially infected by caterpillar leaves $\left(I_{H}\right)$, a population of Palu onion that potentially infected by patches leaves $\left(I_{P}\right)$, a population of Palu onion that is free of pest and disease $(R)$. The other population to be considered to the model are a populations of caterpillar that potentially creates pests $(U)$, a population of fungi that potentially creates disease $(J)$. The constructed model is a nonlinear differensial systemequations, that its stability is analyzed at every critical point using linearization method. There are three obtained critical points. The first one shows that the Palu onion population is free of pest and disease. That critical point is not stable, it means that all populations of caterpillar leaves, fungi altenaria porri and the Palu onion are extinct. The second critical point shows that the Palu onion population is free of pest. That critical point is stable under $\beta_{1}>\beta_{2}$ requirement, it means that number of caterpillar leaves infection is not allowed to exceed the number of patches leaves disease. The third critical point shows that the Palu onion population is endemic. The analysis of the stability interpretes that both unstable critical points will not stay in the population, while the free pest critical point will remain.
\end{abstract}

Keywords : Allium Ascalonicum L., Altenaria Porri, Linearization, Spodoptera Exigue, Stability.

\section{ABSTRAK}

Ulat daun (spodoptera exigue) dan jamur altenaria porri merupakan organisme pengganggu tumbuhan yang menjadi faktor dari beberapa masalah yang dihadapi dalam budidaya bawang merah (Allium ascalonicum L.). Penelitian ini bertujuan untuk mendapatkan model matematika penyebaran hama dan penyakit pada bawang merah Palu, dengan membagi menjadi 6 sub populasi, yaitu $(U)$ sub populasi ulat yang berpotensi menyebarkan hama, $(J)$ populasi jamur yang berpotensi menyebarkan penyakit, $(S)$ populasi bawang merah Palu yang berpotensi terkena hama dan penyakit, $\left(I_{H}\right)$ pupulasi bawang merah Palu yang terinfeksi hama ulat daun, $\left(I_{P}\right)$ populasi bawang merah Palu yang terinfeksi penyakit bercak daun, $(R)$ populasi bawang merah Palu yang bebas hama dan penyakit. Model yang dibangun berupa sistem persamaan differensial tak linear, kemudian dianalisa kestabilannya di setiap titik kritis dengan metode linearisasi. Dari hasil penelitian didapatkan tiga titik kritis. Pertama, titik kritis yang memperlihatkan bawang merah Palu bebas hama dan penyakit. Titik kritis tersebut tidak stabil sehingga seluruh populasi ulat daun, jamur altenaria pori, dan bawang merah Palu akan habis. Kedua, titik kritis 
kedua memperlihatkan bawang merah Palu bebas hama. Titik kritis tersebut stabil dengan syarat $\beta_{1}>\beta_{2}$ yang memberi arti bahwa tingkat serangan hama ulat daun tidak boleh melebihi tingkat serangan penyakit bercak daun. Ketiga, Titik kritis memperlihatkan bawang merah Palu yang endemik. Titik kritis tersebut tidak stabil yang memberi arti bahwa titik kritis tersebut akan ditinggalkan. Hasil analisa kestabilan tersebut disimpulkan bahwa, kedua titik kritis yang tidak stabil tersebut, tidak bersifat menetap. Sedangkan titik kritis bebas hama akan menetap dalam populasi.

Kata Kunci : Allium Ascalonicum L., Altenaria Porri, Linearisasi, Spodoptera Exigue, Kestabilan.

\section{PENDAHULUAN}

Bawang merah Palu ( Allium ascalonicum L.) merupakan salah satu komoditas unggulan yang memberikan kontribusi cukup tinggi terhadap perkembangan ekonomi wilayah, sehingga pengusaha budidaya bawang merah telah menyebar diham pir semua provinsi di Indonesia. SeranganOrganisme Pengganggu Tumbuhan (OPT) yang semakin bertambah merupakan salah satu faktor dari beberapa masalah yang dihadapi dalam budidaya bawang merah.

Hama yang banyak menyerang tanaman bawang merah Palu adalah ulat daun ( spodoptera exigue), sedangkan penyakitnya adalah bercak daun yang disebabkan oleh Alternaria porri Ell. Serangan ulat daun akan diikuti dengan serangan bercak daun mengakibatkan panen bawangmerah Palu turun $40 \%$. Ulat daun mulai menyerang tanaman setelah berumur kurang dari 14 hari, sedangkan bercak daun mulai menyerang setelah tanaman berumur 25 hari. Bawang merah Palu dipanensetelah berumur 65 sampai 70 hari (Maskar dkk, 1999).

Dalam penelitian ini, model yang dikaji menggambarkan dinamika perkembangan dari banyaknya populasi bawang merah yang rentan terhadap hama dan penyakit (suscepted), ke dalam populasi bawang merah yang terinfeksi hama dan penyakit (infected), dan populasi bawang merah yang telah bebas hama penyakit (recovered).

Salah satu model penyebaran penyakit yang sering dikenal model tipe SIR (Suscepted Infected-Recovered) klasik (Kermack, Mc Kendrick, 1927). Dari model tersebut dibangun model baru yang melibatkan faktor hama dan penyakit bercak daun. Penyebaran hama dan penyakit tersebutakan dikaji melalui kestabilan titik kritis sistem yang mem presentasikannya. Kestabilan dari titik kritis dapat diperoleh dengan menggunakan metode linearisasi dan kriteria Routh-Hurwitz (Subiono, 2013).

\section{METODE PENELITIAN}

Penelitian dilakukan dengan mengkonstruksi model dinamik penyebaran hama dan penyakit pada bawang merah Palu yang dibangun dari kompartemen penyebarannya. Titik kritis dari sistem persamaan diferensial yang telah dibangun, selanjutnya dianalisa kestabilannya dengan melakukan linearisasi sistem disekitar titik kritis, sehingga menghasilkan persamaan karakteristik untuk menentukan nilai eigen (Anton, 1998). Nilai eigen diperoleh dari $\left.{ }^{\operatorname{det}(} J-\lambda I\right)=0$, dimana $J$ adalah matiks Jacobi (Perko, 2001:102). 


\section{HASIL DAN PEMBAHASAN}

\subsection{Konstruksi Model}

Penyebaran hama dan penyakit dalam penelitian ini dianalogikan sebagai masalah penyebaran penyakit menular. Penyebaran penyakit menular dapat digambarkan secara sistematis oleh model-model kompartemen SIRyang mengacu pada susceptible, infected,dan recovered. Penyebaran hama dipengaruhi oleh pertumbuhan populasi ulat daun sedangkan penyebaran penyakit dipengaruhi oleh jamur altenaria porri. Keduanya menginfeksi tanaman bawang dalam internal waktu yang berbeda. Berdasarkan fenomena tersebut dikonstruksi kompartemen penyebaran hama dan penyakit pada bawang merah kota Palu sebagai berikut

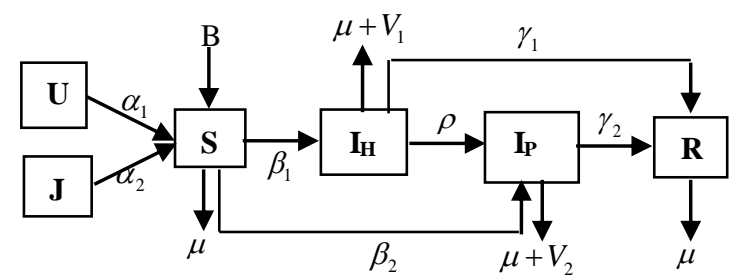

Gambar 1 : Konstruksi Model Penyebaran Hama dan Penyakit pada Bawang Merah Palu Diperoleh sistem persamaannya sebagai berikut:

$$
\begin{aligned}
& \frac{d U}{d t}=\psi_{1} U\left(1-\frac{U}{K}\right) \\
& \frac{d J}{d t}=\psi_{2} J\left(1-\frac{J}{K}\right) \\
& \frac{d S}{d t}=S\left(B+\alpha_{1} U+\alpha_{2} J-\beta_{1} I_{H}-\beta_{2} I_{P}-\mu\right) \\
& \frac{d I_{H}}{d t}=I_{H}\left(\beta_{1} S-\left(\mu+V_{1}\right)-\rho-\gamma_{1}\right) \\
& \frac{d I_{P}}{d t}=I_{P}\left(\beta_{2} S-\left(\mu+V_{2}\right)-\gamma_{2}\right)+\rho I_{H} \\
& \frac{d R}{d t}=\gamma_{1} I_{H}+\gamma_{2} I_{P}-\mu R
\end{aligned}
$$

\subsection{Menentukan Titik Kritis}

Titik kritis dari sistem Persamaan (1) - (6) dapat diperoleh dengan meninjau pada keadaan stagnan, yaitu dengan menentukan $\frac{d U}{d t}=0, \frac{d J}{d t}=0, \frac{d S}{d t}=0, \frac{d I_{H}}{d t}=0, \frac{d I_{P}}{d t}=0, \frac{d R}{d t}=0$

1. Titik kritis pertama

Titik kritis pertama yang menggambarkan kondisi populasi bawang merah Palu bebas hama dan penyakit $T_{1}=(0,0,0,0,0,0)$.

2. Titik Kritis kedua

Titik kritis kedua yang menggambarkan kondisi populasi bawang merah Palu bebas hama $T_{2}=\left(K, K, \frac{\mu+V_{2}+\gamma_{2}}{\beta_{2}}, 0, \frac{B+\alpha_{1} K+\alpha_{2} K-\mu}{\beta_{2}}, \frac{\gamma_{2}\left(B+\alpha_{1} K+\alpha_{2} K-\mu\right)}{\beta_{2} \mu}\right)$. 
Eksistensi titik kritis $T_{2}$, dapat tercapai jika $U, J, S, I_{H}, I_{P}, R$ bernilai non negatif. Mengingat $U_{2}=K, J_{2}=K, S_{2}=\frac{\mu+V_{2}+\gamma_{2}}{\beta_{2}}$, dan $I_{P_{2}}=\frac{B+\alpha_{1} K+\alpha_{2} K-\mu}{\beta_{2}}$ yang non negatif, maka eksistensi bagi $T_{2}$ membutuhkan syarat $B+\alpha_{1} K+\alpha_{2} K-\mu>0$ sehingga $\mu<B+K\left(\alpha_{1}+\alpha_{2}\right)$.

Syarat tersebut menginterpretasikan bahwa eksistensi $T_{2}$ terpenuhi jika tinggkat kematian alaminya terbatasi oleh faktor rekruitmen dari bawang merah Palu, laju infeksi hama, laju infeksi penyakit, dan daya tampung populasi bawang sebagai sumber makanan bagi ulat daun dan jamur altenaria porri.

\section{Titik Kritis ketiga}

Titik kritis ketiga yang menggam barkan kondisi populasi bawang merah terseranghama dan penyakit, $T_{3}=\left(K, K, \frac{\mu+V_{1}+\rho+\gamma_{1}}{\beta_{1}}, \frac{\left(B+\alpha_{1} K+\alpha_{2} K-\mu\right)\left(\beta_{2}\left(\mu+V_{1}+\rho+\gamma_{1}\right)-\beta_{1}\left(\mu+V_{2}+\gamma_{2}\right)\right)}{\beta_{1}\left(\beta_{2}\left(\mu+V_{1}+\gamma_{1}\right)-\beta_{1}\left(\mu+V_{2}+\gamma_{2}\right)\right)}\right.$, $\left.\frac{-\rho\left(B+\alpha_{1} K+\alpha_{2} K-\mu\right)}{\beta_{2}\left(\mu+V_{1}+\gamma_{1}\right)-\beta_{1}\left(\mu+V_{2}+\gamma_{2}\right)}, \frac{\gamma_{1}\left(\left(B+\alpha_{1} K+\alpha_{2} K-\mu\right)\left(\beta_{2}\left(\mu+V_{1}+\rho+\gamma_{1}\right)-\beta_{1}\left(\mu+V_{2}+\gamma_{2}\right)\right)\right)}{\beta_{1} \mu\left(\beta_{2}\left(\mu+V_{1}+\gamma_{1}\right)-\beta_{1}\left(\mu+V_{2}+\gamma_{2}\right)\right)}\right)$

Eksistensi titik kritis $T_{3}$, tercapai jika $U, J, S, I_{H}, I_{P}, R$ bernilai non negatif. Mengingat $U_{3}=K, J_{3}=K$, dan $S_{3}=\frac{\mu+V_{1}+\rho+\gamma_{1}}{\beta_{1}}$ bernilai positif, maka jaminan eksistensi $T_{3}$ dipenuhi jika $I_{H_{3}}, I_{P_{3}}$, dan $R_{3}$ yang bernilai non negatif. Agar $I_{H_{3}}, I_{P_{3}}$, dan $R_{3}$ tidak negatif, maka harus dipenuhi $\left(B+\alpha_{1} K+\alpha_{2} K-\mu\right)\left(\beta_{2}\left(\mu+V_{1}+\rho+\gamma_{1}\right)-\beta_{1}\left(\mu+V_{2}+\gamma_{2}\right)\right)>0$. Sehingga disimpulkan bahwa syarat eksistensi bagi $T_{3}$ adalah $\mu<\frac{\beta_{2}\left(V_{1}+\gamma_{1}\right)-\beta_{1}\left(V_{2}+\gamma_{2}\right)}{\beta_{1}-\beta_{2}}$ dan $\mu<B+K\left(\alpha_{1}+\alpha_{2}\right)$. Syarat tersebut memberi arti bahwa tingkat kematian alami bawang merah Palu harus dibatasi.

\subsection{Analisis Kestabilan Titik Kritis}

\subsubsection{Kestabilan Titik Kritis $T_{1}$}

Titik kritis pertama adalah titik kritis yang menggambarkan keadaan populasi bawang merah palu yang bebas hama dan penyakit. Kestabilan di titik kritis tersebut diperoleh berdasarkan nilai eigen dari linearisasi sistem melalui matriks Jacobi yang dievaluasi pada $T_{1}=(0,0,0,0,0,0)$ sehingga diperoleh

$$
A_{1}=\left[\begin{array}{cccccc}
\psi_{1} & 0 & 0 & 0 & 0 & 0 \\
0 & \psi_{2} & 0 & 0 & 0 & 0 \\
0 & 0 & B-\mu & 0 & 0 & 0 \\
0 & 0 & 0 & -\rho-\left(\mu+V_{1}\right)-\gamma_{1} & 0 & 0 \\
0 & 0 & 0 & \rho & -\gamma_{2}-\left(\mu+V_{2}\right) & 0 \\
0 & 0 & 0 & \gamma_{1} & \gamma_{2} & -\mu
\end{array}\right]
$$

Nilai eigen $A_{1}$ diperoleh dari $\operatorname{det}\left(A_{1}-\lambda I\right)=0$

$$
\left(\psi_{1}-\lambda\right)\left(\psi_{2}-\lambda\right)(B-\mu-\lambda)\left(-\rho-\mu-V_{1}-\gamma_{1}-\lambda\right)\left(-\gamma_{2}-\mu-V_{2}-\lambda\right)(-\mu-\lambda)=0
$$


Mengingat $\lambda_{1}=\psi_{1}$ dan $\lambda_{2}=\psi_{2}$ maka kestabilan sistem di titik kritis $T_{1}$ dapat ditentukan dari kedua nilai eigen tersebut yang bernilai positif. Dapat disimpulkan bahwa $T_{1}$ adalah tidak stabil.

\subsubsection{Kestabilan Titik Kritis $\mathrm{T}_{2}$}

Titik kritis kedua adalah titik kritis yang menggambarkan keadaan populasi bawang merah palu yang bebas hama. Mengingat titik kritis kedua $T_{2}=\left(K, K, \frac{\mu+V_{2}+\gamma_{2}}{\beta_{2}}, 0, \frac{B+\alpha_{1} K+\alpha_{2} K-\mu}{\beta_{2}}, \frac{\gamma_{2}\left(B+\alpha_{1} K+\alpha_{2} K-\mu\right)}{\beta_{2} \mu}\right)$ bukan titik kritis nol, maka analisa kestabilan titik kritis tersebut dilakukan dengan mentransformasi variabel $U, J, S, I_{H}, I_{P}$, dan $R$ terlebih dahulu, sehingga Persamaan (1) - (6) dianalisa di titik kritis $(0,0,0,0,0,0)$ dalam sisitem koordinat baru. Sehingga diperoleh persamaan baru dalam $\left(Z, Y, X, I_{H}, W, T\right)$ :

$$
\begin{aligned}
& a=\frac{d Z}{d t}=(K+Z)\left(\psi_{1}-\frac{\psi_{1}(K+Z)}{K}\right) \\
& b=\frac{d Y}{d t}=(K+Y)\left(\psi_{2}-\frac{\psi_{2}(K+Y)}{K}\right) \\
& c=\frac{d X}{d t}=\left(\frac{\mu+V_{2}+\gamma_{2}}{\beta_{2}}+X\right)\left(B+\alpha_{1}(K+Z)+\alpha_{2}(K+Y)-\beta_{1} I_{H}-\beta_{2}\left(\frac{B+\alpha_{1} K+\alpha_{2} K-\mu}{\beta_{2}}+W\right)-\mu\right) \\
& d=\frac{d I_{H}}{d t}=I_{H}\left(\beta_{1}\left(\frac{\mu+V_{2}+\gamma_{2}}{\beta_{2}}+X\right)-\left(\mu+V_{1}\right)-\rho-\gamma_{1}\right) \\
& e=\frac{d W}{d t}=\left(\frac{B+\alpha_{1} K+\alpha_{2} K-\mu}{\beta_{2}}+W\right)\left(\beta_{2}\left(\frac{\mu+V_{2}+\gamma_{2}}{\beta_{2}}+X\right)-\left(\mu+V_{2}\right)-\gamma_{2}\right)+\rho I_{H} \\
& f=\frac{d T}{d t}=\gamma_{1} I_{H}+\gamma_{2}\left(\frac{B+\alpha_{1} K+\alpha_{2} K-\mu}{\beta_{2}}+W\right)-\mu\left(\frac{\gamma_{2}\left(B+\alpha_{1} K+\alpha_{2} K-\mu\right)}{\beta_{2} \mu}+T\right)
\end{aligned}
$$

Selanjutnya dapat dibentuk matriks Jacobi dari Persamaan (7) - (12) yang di evaluasi dititik kritis $T_{2}=(0,0,0,0,0,0)$ sehingga didapat:

$$
A_{2}=\left[\begin{array}{cccccc}
-\psi_{1} & 0 & 0 & 0 & 0 & 0 \\
0 & -\psi_{2} & 0 & 0 & 0 & 0 \\
\frac{\alpha_{1}\left(\mu+V_{2}+\gamma_{2}\right)}{\beta_{2}} & \frac{\alpha_{2}\left(\mu+V_{2}+\gamma_{2}\right)}{\beta_{2}} & 0 & \frac{-\beta_{1}\left(\mu+V_{2}+\gamma_{2}\right)}{\beta_{2}} & -\left(\mu+V_{2}+\gamma_{2}\right) & 0 \\
0 & 0 & 0 & \frac{\beta_{1}\left(\mu+V_{2}+\gamma_{2}\right)}{\beta_{2}}-\left(\mu+V_{1}\right)-\rho-\gamma_{1} & 0 & 0 \\
0 & 0 & B+\alpha_{1} K+\alpha_{2} K-\mu & \rho & 0 & 0 \\
0 & 0 & 0 & \gamma_{1} & \gamma_{2} & -\mu
\end{array}\right]
$$

Nilai eigen $A_{2}$ diperoleh dari $\operatorname{det}\left(A_{2}-\lambda I\right)=0$

$$
\left(-\psi_{1}-\lambda\right)\left(-\psi_{2}-\lambda\right)\left(\frac{\beta_{1}\left(\mu+V_{2}+\gamma_{2}\right)}{\beta_{2}}-\left(\mu+V_{1}\right)-\rho-\gamma_{1}-\lambda\right)(-\mu-\lambda)\left(a_{0} \lambda^{2}+a_{2}\right)=0
$$

Dari Persamaan (6) diperoleh nilai eigen yaitu, $\lambda_{1}=-\psi_{1}, \quad \lambda_{2}=-\psi_{2}$ $\lambda_{3}=\frac{\beta_{1}\left(\mu+V_{2}+\gamma_{2}\right)}{\beta_{2}}-\rho-\mu-V_{1}-\gamma_{1}, \lambda_{4}=-\mu_{3}$, dan $\lambda_{5,6}= \pm i \sqrt{\frac{a_{2}}{a_{0}}}$. Mengingat $\lambda_{1}, \lambda_{2}, \lambda_{4}$ bernilai negatif, sedangkan $\lambda_{5}$ dan $\lambda_{6}$ memiliki bagian riil bernilai nol, maka kestabilan sistem 
di titik $T_{2}$ ditentukan oleh nilai $\lambda_{3}$. Sehingga syarat kestabilan untuk $T_{2}$ adalah $\lambda_{3}<0$, yaitu $\beta_{1}\left(\mu+V_{2}+\gamma_{2}\right)<\beta_{2}\left(\rho+\mu+V_{1}+\gamma_{1}\right)$ yang memberikan $\mu<\frac{\beta_{2}}{\beta_{1}-\beta_{2}}\left(\rho+V_{1}+\gamma_{1}\right)$.

Syarat tersebut memberikan arti bahwa tingkat kematian alami bawang merah Palu harus dibatasi. Syarat lain yang harus dipenuhi adalah $\beta_{1}>\beta_{2}$ yang memberi arti tingkat serangan penyakit bercak daun tidak boleh melebihi tingkat serangan hamaulat daun.

\subsubsection{Kestabilan Titik Kritis $T_{3}$}

Titik kritis ketiga adalah titik kritis yang menggambarkan keadaan populasi bawang merah palu yang endemik. Seperti halnya titik kritis kedua, titik kritis ketiga

$$
\begin{aligned}
& T_{3}=\left(K, K, \frac{\mu+V_{1}+\rho+\gamma_{1}}{\beta_{1}}, \frac{\left(B+\alpha_{1} K+\alpha_{2} K-\mu\right)\left(\beta_{2}\left(\mu+V_{1}+\rho+\gamma_{1}\right)-\beta_{1}\left(\mu+V_{2}+\gamma_{2}\right)\right)}{\beta_{1}\left(\beta_{2}\left(\mu+V_{1}+\gamma_{1}\right)-\beta_{1}\left(\mu+V_{2}+\gamma_{2}\right)\right)},\right. \\
& \left.\frac{-\rho\left(B+\alpha_{1} K+\alpha_{2} K-\mu\right)}{\beta_{2}\left(\mu+V_{1}+\gamma_{1}\right)-\beta_{1}\left(\mu+V_{2}+\gamma_{2}\right)}, \frac{\gamma_{1}\left(\left(B+\alpha_{1} K+\alpha_{2} K-\mu\right)\left(\beta_{2}\left(\mu+V_{1}+\rho+\gamma_{1}\right)-\beta_{1}\left(\mu+V_{2}+\gamma_{2}\right)\right)\right)}{\beta_{1} \mu\left(\beta_{2}\left(\mu+V_{1}+\gamma_{1}\right)-\beta_{1}\left(\mu+V_{2}+\gamma_{2}\right)\right)}\right)
\end{aligned}
$$

bukan titik kritis nol, maka analisa kestabilan titik kritis tersebut dilakukan dengan mentransformasi variabel $U, J, S, I_{H}, I_{P}$, dan $R$ terlebih dahulu. Sehingga diperoleh persamaan baru dalam $(Z, Y, X, \mathrm{Q}, W, T)$ :

$$
\begin{aligned}
& a=\frac{d Z}{d t}=(K+Z)\left(\psi_{1}-\frac{\psi_{1}(K+Z)}{K}\right) \\
& b=\frac{d Y}{d t}=(K+Y)\left(\psi_{2}-\frac{\psi_{2}(K+Y)}{K}\right) \\
& c=\frac{d X}{d t}=\left(\frac{\mu+V_{1}+\rho+\gamma_{1}}{\beta_{1}}+X\right)\left(B+\alpha_{1}(K+Z)+\alpha_{2}(K+Y)-\right. \\
& \beta_{1}\left(\frac{\left(B+\alpha_{1} K+\alpha_{2} K-\mu\right)\left(\beta_{2}\left(\mu+V_{1}+\rho+\gamma_{1}\right)-\beta_{1}\left(\mu+V_{2}+\gamma_{2}\right)\right)}{\beta_{1}\left(\beta_{2}\left(\mu+V_{1}+\gamma_{1}\right)-\beta_{1}\left(\mu+V_{2}+\gamma_{2}\right)\right)}+Q\right) \\
& \left.-\beta_{2}\left(\frac{-\rho\left(B+\alpha_{1} K+\alpha_{2} K-\mu\right)}{\beta_{2}\left(\mu+V_{1}+\gamma_{1}\right)-\beta_{1}\left(\mu+V_{2}+\gamma_{2}\right)}+W\right)-\mu_{3}\right) \\
& d=\frac{d Q}{d t}=\left(\frac{\left(B+\alpha_{1} K+\alpha_{2} K-\mu\right)\left(\beta_{2}\left(\mu+V_{1}+\rho+\gamma_{1}\right)-\beta_{1}\left(\mu+V_{2}+\gamma_{2}\right)\right)}{\beta_{1}\left(\beta_{2}\left(\mu+V_{1}+\gamma_{1}\right)-\beta_{1}\left(\mu+V_{2}+\gamma_{2}\right)\right)}+Q\right) \\
& \left(\beta_{1}\left(\frac{\mu+V_{1}+\rho+\gamma_{1}}{\beta_{1}}+X\right)-\left(\mu+V_{1}\right)-\rho-\gamma_{1}\right) \\
& e=\frac{d W}{d t}=\left(\frac{-\rho\left(B+\alpha_{1} K+\alpha_{2} K-\mu\right)}{\beta_{2}\left(\mu+V_{1}+\gamma_{1}\right)-\beta_{1}\left(\mu+V_{2}+\gamma_{2}\right)}+W\right)\left(\beta_{2}\left(\frac{\mu+V_{1}+\rho+\gamma_{1}}{\beta_{1}}+X\right)-\left(\mu+V_{2}\right)-\gamma_{2}\right)+ \\
& \rho\left(\frac{\left(B+\alpha_{1} K+\alpha_{2} K-\mu\right)\left(\beta_{2}\left(\mu+V_{1}+\rho+\gamma_{1}\right)-\beta_{1}\left(\mu+V_{2}+\gamma_{2}\right)\right)}{\beta_{1}\left(\beta_{2}\left(\mu+V_{1}+\gamma_{1}\right)-\beta_{1}\left(\mu+V_{2}+\gamma_{2}\right)\right)}+Q\right)
\end{aligned}
$$




$$
\begin{aligned}
f=\frac{d T}{d t}= & \gamma_{1}\left(\frac{\left(B+\alpha_{1} K+\alpha_{2} K-\mu\right)\left(\beta_{2}\left(\mu+V_{1}+\rho+\gamma_{1}\right)-\beta_{1}\left(\mu+V_{2}+\gamma_{2}\right)\right)}{\beta_{1}\left(\beta_{2}\left(\mu+V_{1}+\gamma_{1}\right)-\beta_{1}\left(\mu+V_{2}+\gamma_{2}\right)\right)}+Q\right) \\
& +\gamma_{2}\left(\frac{-\rho\left(B+\alpha_{1} K+\alpha_{2} K-\mu\right)}{\beta_{2}\left(\mu+V_{1}+\gamma_{1}\right)-\beta_{1}\left(\mu+V_{2}+\gamma_{2}\right)}+W\right)- \\
& \mu_{3}\left(\frac{\gamma_{1}\left(\left(B+\alpha_{1} K+\alpha_{2} K-\mu\right)\left(\beta_{2}\left(\mu+V_{1}+\rho+\gamma_{1}\right)-\beta_{1}\left(\mu+V_{2}+\gamma_{2}\right)\right)\right)}{\beta_{1} \mu\left(\beta_{2}\left(\mu+V_{1}+\gamma_{1}\right)-\beta_{1}\left(\mu+V_{2}+\gamma_{2}\right)\right)}+T\right)
\end{aligned}
$$

Selanjutnya dapat dibentuk matriks Jacobi dari Persamaan (13) - (18) yang di evaluasi dititik kritis $T_{3}=(0,0,0,0,0,0)$, sehingga diperoleh:

$$
A_{3}=\left[\begin{array}{cccccc}
-\psi_{1} & 0 & 0 & 0 & 0 & 0 \\
0 & -\psi_{2} & 0 & 0 & 0 & 0 \\
\frac{\alpha_{1}\left(\mu+V_{1}+\rho+\gamma_{1}\right)}{\beta_{1}} & \frac{\alpha_{2}\left(\mu+V_{1}+\rho+\gamma_{1}\right)}{\beta_{1}} & 0 & -\left(\mu+V_{1}+\rho+\gamma_{1}\right) & \frac{-\beta_{2}\left(\mu+V_{1}+\rho+\gamma_{1}\right)}{\beta_{1}} & 0 \\
0 & 0 & \frac{\left(B+\alpha_{1} K+\alpha_{2} K-\mu\right)\left(\beta_{2}\left(\mu+V_{1}+\rho+\gamma_{1}\right)-\beta_{1}\left(\mu+V_{2}+\gamma_{2}\right)\right)}{\left(\beta_{2}\left(\mu+V_{1}+\gamma_{1}\right)-\beta_{1}\left(\mu+V_{2}+\gamma_{2}\right)\right)} & 0 & 0 & 0 \\
0 & 0 & \frac{-\beta_{2} \rho\left(B+\alpha_{1} K+\alpha_{2} K-\mu\right)}{\beta_{2}\left(\mu+V_{1}+\gamma_{1}\right)-\beta_{1}\left(\mu+V_{2}+\gamma_{2}\right)} & \rho & \frac{\beta_{2}\left(\mu+V_{1}+\rho+\gamma_{1}\right)}{\beta_{1}} & 0 \\
0 & 0 & 0 & \gamma_{1} & -\left(\mu+V_{2}\right)-\gamma_{2} & \\
\gamma_{2} & 0 & 0 & -\mu
\end{array}\right]
$$

Nilai eigen $A_{3}$ diperoleh dari $\operatorname{det}\left(A_{3}-\lambda I\right)=0$, yaitu

$$
\begin{aligned}
& \left(-\psi_{1}-\lambda\right)\left(-\psi_{2}-\lambda\right)(-\mu-\lambda)\left(\lambda^{3}-\lambda^{2}\left(\frac{\beta_{2}\left(\mu+V_{1}+\rho+\gamma_{1}\right)}{\beta_{1}}-\left(\mu+V_{2}\right)-\gamma_{2}\right)-\right. \\
& \lambda\left(\frac{\left(B+\alpha_{1} K+\alpha_{2} K-\mu\right)\left(\beta_{2}\left(\mu+V_{1}+\rho+\gamma_{1}\right)-\beta_{1}\left(\mu+V_{2}+\gamma_{2}\right)\right)}{\left(\beta_{2}\left(\mu+V_{1}+\gamma_{1}\right)-\beta_{1}\left(\mu+V_{2}+\gamma_{2}\right)\right)}\right)\left(-\left(\mu+V_{1}+\rho+\gamma_{1}\right)\right)- \\
& \lambda\left(\frac{-\beta_{2} \rho\left(B+\alpha_{1} K+\alpha_{2} K-\mu\right)}{\beta_{2}\left(\mu+V_{1}+\gamma_{1}\right)-\beta_{1}\left(\mu+V_{2}+\gamma_{2}\right)}\right)\left(\frac{-\beta_{2}\left(\mu+V_{1}+\rho+\gamma_{1}\right)}{\beta_{1}}\right)- \\
& \left(\frac{\left(B+\alpha_{1} K+\alpha_{2} K-\mu\right)\left(\beta_{2}\left(\mu+V_{1}+\rho+\gamma_{1}\right)-\beta_{1}\left(\mu+V_{2}+\gamma_{2}\right)\right)}{\left(\beta_{2}\left(\mu+V_{1}+\gamma_{1}\right)-\beta_{1}\left(\mu+V_{2}+\gamma_{2}\right)\right)}\right)(\rho)\left(\frac{-\beta_{2}\left(\mu+V_{1}+\rho+\gamma_{1}\right)}{\beta_{1}}\right)+ \\
& \left(\frac{\left(B+\alpha_{1} K+\alpha_{2} K-\mu\right)\left(\beta_{2}\left(\mu+V_{1}+\rho+\gamma_{1}\right)-\beta_{1}\left(\mu+V_{2}+\gamma_{2}\right)\right)}{\left(\beta_{2}\left(\mu+V_{1}+\gamma_{1}\right)-\beta_{1}\left(\mu+V_{2}+\gamma_{2}\right)\right)}\right)\left(-\left(\mu+V_{1}+\rho+\gamma_{1}\right)\right) \\
& \left.\left(\frac{\beta_{2}\left(\mu+V_{1}+\rho+\gamma_{1}\right)}{\beta_{1}}-\left(\mu+V_{2}\right)-\gamma_{2}\right)\right)=0
\end{aligned}
$$

Persamaan (19) dapat disederhanakan menjadi

$$
\left(-\psi_{1}-\lambda\right)\left(-\psi_{2}-\lambda\right)(-\mu-\lambda)\left(a_{0} \lambda^{3}+a_{1} \lambda^{2}+a_{2} \lambda+a_{3}\right)=0
$$

Persamaan (20) memberikan nilai negatifpada $\lambda_{1}, \lambda_{2}$ dan $\lambda_{3}$, sehingga kestabilan titik kritis $T_{3}$ ditentukan oleh persamaan karakteristik

$$
\left(a_{0} \lambda^{3}+a_{1} \lambda^{2}+a_{2} \lambda+a_{3}\right)=0
$$

Tanda dari nilai eigen yang diperoleh pada persamaan (21) ditentukan melalui polinomial berderajat tiga dalam $\lambda$ pada persamaan (21) yang dinyatakan dalam Tabel Routh-Hurwitz sebagai berikut.

Tabel 1 : Routh-Hurwitz 
\begin{tabular}{c|cc}
$\lambda^{3}$ & $a_{0}$ & $a_{2}$ \\
\hline$\lambda^{2}$ & $a_{1}$ & $a_{3}$ \\
$\lambda^{1}$ & $b_{1}$ & $b_{2}$ \\
$\lambda^{0}$ & $c_{1}$ &
\end{tabular}

Syarat kriteria Routh-Hurwitz memerlukan pemeriksaan terhadap setiap koefisen dan tidak adanya perubahan tanda pada kolom pertama. Mengingat $a_{0}=1$, maka perlu diperiksa $a_{1}>0 \quad b_{1}>0$, dan $c_{1}>0$. Mengingat $\beta_{1}, \beta_{2}, \mu, V_{1}, \rho, \gamma_{1}, V_{2}$, dan $\gamma_{2}$ adalah positif maka $a_{1}=-\frac{\beta_{2}\left(\mu+V_{1}+\rho+\gamma_{1}\right)}{\beta_{1}}-\left(\mu+V_{2}\right)-\gamma_{2}<0$. Sehingga menunjukan terjadinya perubahan tanda pada kolom pertama tabel Routh-Hurwitz. Disimpulkan bahwa $T_{3}$ adalah tidak stabil.

\subsection{Simulasi}

Simulasi model penyebaran hama dan penyakit pada bawang merah Palu dilakukan menggunakan perangkat lunak Maple13 dengan memberikan nilai - nilai awal kelompok populasi ulat $(U)=2224$ ekor, populasi jamur $(\mathrm{J})=5560$ daun, populasi bawang merah Palu yang rentan $(S)=4448$ rum pun, populasi bawang merah Palu yang terinfeksi hama $\left(I_{H}\right)=1112$ rumpun, populasi bawang merah Palu yang terinfeksi penyakit $\left(I_{P}\right)=556$ rumpun, dan bawang merah Palu bebas hama dan penyakit $(R)=2780$ rumpun. Dengan nilai -nilai parameternya yaitu, laju kelahiran ulat daun $\left(\psi_{1}\right)=158,85$, laju kelahiran jamur $\left(\psi_{2}\right)=158,85$, tingkat rekruitmen bawang merah Palu $(B)=68,43$, laju infeksi hama ke bawang merah Palu yang rentan $\left(\alpha_{1}\right)=0,5$, laju infeksi jamur ke bawang merah Palu yang rentan $\left(\alpha_{2}\right)=1,25$, laju kematian alami bawang merah Palu $(\mu)=0,015$, transmisi hama ulat daun $\left(\beta_{1}\right)=0,25$, transmisi penyakit bercak daun $\left(\beta_{2}\right)=0,125$, laju transisi yang terinfeksi hama $(\rho)=0,5$, kematian alami bawang merah Palu yang terinfeksi hama $\left(V_{1}\right)=0,071$, kematian alami bawang merah Palu yang terinfeksi penyakit $\left(V_{2}\right)=0,016$, laju penyembuhan bawang merah palu yang terinfeksi hama $\left(\gamma_{1}\right)=2,41$, dan laju penyembuhan bawang merah palu yang terinfeksi penyakit $\left(\gamma_{2}\right)=4,82$. Interval waktu pengamatan dibuat dalam tahun.

\section{KESIMPULAN}

Berdasarkan penelitian yang telah dilakukan dapat disimpulkan bahwa, kestabilan pada titik kritis bawang merah Palu bebas hama dan penyakit yang diekspresikan sebagai $T_{1}=(0,0,0,0,0,0)$ menunjukan bahwa sistem tidak stabil. Titik kritis tersebut akan mengakibatkan seluruh populasi ulat daun, jamur altenaria porri, dan bawang merah Palu akan habis. Untuk kestabilan pada titik kritis bawang merah Palu bebas hama yang diekspresikan sebagai $T_{2}=\left(K, K, \frac{\mu+V_{2}+\gamma_{2}}{\beta_{2}}, 0, \frac{B+\alpha_{1} K+\alpha_{2} K-\mu}{\beta_{2}}, \frac{\gamma_{2}\left(B+\alpha_{1} K+\alpha_{2} K-\mu\right)}{\beta_{2} \mu}\right)$ menunjukan bahwa sistem stabil dengan syarat $\mu<\frac{\beta_{2}}{\beta_{1}-\beta_{2}}\left(\rho+V_{1}+\gamma_{1}\right)$ memberi arti tingkat serangan penyakit bercak daun tidak boleh melebihi tingkat serangan hama ulat daun. Sedangkan kestabilan pada titik kritis bawang merah Palu yang 
endemik diekspresikan sebagai $T_{3}=\left(K, K, \frac{\mu+V_{1}+\rho+\gamma_{1}}{\beta_{1}}, \frac{\left(B+\alpha_{1} K+\alpha_{2} K-\mu\right)\left(\beta_{2}\left(\mu+V_{1}+\rho+\gamma_{1}\right)-\beta_{1}\left(\mu+V_{2}+\gamma_{2}\right)\right)}{\beta_{1}\left(\beta_{2}\left(\mu+V_{1}+\gamma_{1}\right)-\beta_{1}\left(\mu+V_{2}+\gamma_{2}\right)\right)}\right.$, $\left.\frac{-\rho\left(B+\alpha_{1} K+\alpha_{2} K-\mu\right)}{\beta_{2}\left(\mu+V_{1}+\gamma_{1}\right)-\beta_{1}\left(\mu+V_{2}+\gamma_{2}\right)}, \frac{\gamma_{1}\left(\left(B+\alpha_{1} K+\alpha_{2} K-\mu\right)\left(\beta_{2}\left(\mu+V_{1}+\rho+\gamma_{1}\right)-\beta_{1}\left(\mu+V_{2}+\gamma_{2}\right)\right)\right)}{\beta_{1} \mu\left(\beta_{2}\left(\mu+V_{1}+\gamma_{1}\right)-\beta_{1}\left(\mu+V_{2}+\gamma_{2}\right)\right)}\right)$ menunjukan bahwa sistem tidak stabil. Ketidak stabilan $T_{3}$ memberi arti bahwa titik kritis tersebut akan ditingalkan.

\section{DAFTAR PUSTAKA}

[1]. Anton, H., Aljabar Linear Elementer: Terjemahan oleh Pantur Silaban, Erlangga, 1998, Jakarta.

[2]. Kermack, W. O. and McKendrick, A. G., A Contribution to the Mathematical Theory of Epidemics, 1927, Royal Society, 115: 700-721.

[3]. Maskar., Sumarni, A. Kadir., dan Chatidjah., Pengaruh ukuran bibit dan jarak tanam terhadap hasil panen bawang merah varietas lokal Palu, Balai Pengkajian Teknologi Pertanian Sulawesi Tengah, 1999, Palu, hlm. 51-56.

[4]. Perko, L., Differential Equations and Dynamical Systems, 3rd, Springer: 2001, New York.

[5]. Subiono., Sistem linear dan Kontrol Optimal, Institut Teknologi Sepuluh Nopember, 2013, Surabaya. 